\title{
Benefits and Risks of Adolescent Strength Training
}

\author{
Ting Liao, Shaohua Xu \\ ${ }^{1 .}$ Sports Training School, Wuhan Sports University, Luoyu Road 461, 430079. Wuhan, P.R. China \\ 2. Shuiguo Lake No.1 Middle School, Wuhan Hubei, 430071, P.R. China liaoting1982126@126.com
}

\begin{abstract}
With the improvement of sports techniques and performances, adolescents can thus promote their physical health. However, the research on strength quality training of adolescents has been very controversial all the time. Despite of this, more current studies have proved that adolescents can promote their physical fitness through the correct direction of the gradual model of strength quality training. Owing to the scientific classifications, there is a summary of the Guide to Strength Training for Adolescents which is internationally used. In general, the work provides a reference for the research of domestic adolescents' strength training.
\end{abstract} China.

Keywords-strength training; benefits; risks; adolescent;

\section{INTRODUCTION}

Strength quality is an important component of the overall physical fitness development of adolescents. It reflects the work-efficiency produced by the movement system of human body when corresponding to the outer stimulus or resistance. With the guarantee of a high strength quality, adolescents can find it easier to fully develop the other aspects of physical fitness ${ }^{[1]}$. In the fields of modern physical training, resistance exercise is mainly utilized for the training of strength quality. In other words, multiple types of resistance load, movement velocity and resistance form are applied to enhance the maximal force, explosive power, exercise tolerance and volume of muscles. With the improvement of sports techniques and performances, adolescents can thus promote their physical health. However, the research on strength quality training of adolescents has been very controversial all the time. Despite of this, more current studies have proved that adolescents can promote their physical fitness through the correct direction of the gradual model of strength quality training. Strength training of muscles and bones is also listed as one of the major sports types beneficial for adolescents' health ${ }^{[2]}$ This work systematically introduced the related research achievements, and analyzed the risks and benefits of strength training for adolescents. Owing to the scientific classifications, there is a summary of the Guide to Strength Training for Adolescents which is internationally used. In general, the work provides a reference for the research of domestic adolescents' strength training.

\section{RISKS OF STRENGTH TRAINING FOR ADOLESCENTS}

Due to the relatively high occurrence rate of sports injury, children and adolescents generally avoid engaging in strength training so as to protect them from getting hurt. For many sports participants, taking part in strength training at an early age would severely damage the cartilage growth. Nevertheless, what actually give rise to injury in practice are the incorrect movements, inappropriate amount of load and inadequate scientific supervision and assistance ${ }^{[3]}$. In spite that the growing cartilage is softer than the neighboring connective tissues, it does not mean that strength training can hurt musculoskeletal systems. Moreover, few adolescents hurt their growth cartilage in sports and exercise according to all the relative studies. Scientific research also fails to manifest that the strength training has side effects on the body growth of adolescents. But in reflection of the various aesthetic sports (such as gymnastics and martial arts) and the leisure sports activities (such as running and playing catch up), adolescents are always found participating in training overloaded in time and magnitude. This kind of training cannot provide correct guidance and supervision for adolescents. For example, in land sports and games, the ground reaction factor generated by jumping and falling can reach five to seven times of the player's own weight ${ }^{[4]}$. For adolescents, strength training has potential risks of causing injury just as other physical activities do. Therefore, to better train adolescent strength, trainers are required to envisage the potential risks and exert scientific and effective instruction and monitor so as to avoid unnecessary injuries (See Figure 1).

\begin{tabular}{|c|c|}
\hline Injury factors & Direction for correction \\
\hline $\begin{array}{ll}\text { Unsafe } & \text { sports } \\
\text { environment }\end{array}$ & $\begin{array}{l}\text { Making sure that the training field is large } \\
\text { enough and well laid-out }\end{array}$ \\
\hline $\begin{array}{l}\text { Incorrect storage of } \\
\text { sports apparatus }\end{array}$ & Safe storage of sports apparatus \\
\hline $\begin{array}{l}\text { Inappropriate usage } \\
\text { of sports apparatus }\end{array}$ & Adding security guidelines in training zones \\
\hline $\begin{array}{l}\text { Excessive increase of } \\
\text { load }\end{array}$ & $\begin{array}{l}\text { Playing sports and make plans according to the } \\
\text { stipulated techniques of movement model }\end{array}$ \\
\hline $\begin{array}{l}\text { Wrong } \quad \text { sports } \\
\text { technique }\end{array}$ & $\begin{array}{l}\text { Making clear instructions and corrective } \\
\text { feedback to sports models }\end{array}$ \\
\hline $\begin{array}{l}\text { Insufficient trunk } \\
\text { control }\end{array}$ & Conducting targeted neuromuscular training \\
\hline $\begin{array}{l}\text { imbalanced muscular } \\
\text { development }\end{array}$ & $\begin{array}{l}\text { Incorporating exercise of agonist and } \\
\text { antagonistic muscles into the training plan }\end{array}$ \\
\hline $\begin{array}{l}\text { Injuries on an early } \\
\text { stage }\end{array}$ & $\begin{array}{l}\text { Communicating with the clinicians over the } \\
\text { revision plan }\end{array}$ \\
\hline $\begin{array}{l}\text { Development } \\
\text { between different } \\
\text { genders }\end{array}$ & Making up for the specific weakness \\
\hline Incomplete recovery & $\begin{array}{l}\text { Combining the enthusiasm with exercise and } \\
\text { taking into consideration of lifestyles, such as } \\
\text { malnutrition and insufficient sleep }\end{array}$ \\
\hline
\end{tabular}

Figure 1. Injury factors in adolescent strength training and the direction for correction 
All types of recommended exercise have risks and benefits. But the risks of injury can be minimized as long as the trainers and trainees observe the following directions: correct training and monitoring, suitable training plans, proper increase of load and prudent selection of sports apparatus. In addition, the trainers should also pay more attention to the total amount of load for a single training, allow adequate time for break and listen carefully to the questions and worries of trainees. In a word, since both adolescents and adults can get hurt in strength training, it is lack of scientific evidence to prevent adolescents from taking part in strength training.

\section{BENEFITS OF ADOLESCENT STRENGTH TRAINING}

According to the current studies, adolescents can benefit quite a lot from strength training. An increasing number of adolescents regularly participate in the strength training suitable for their age and growth degree. For these adolescents, they can keep a healthy habit of doing sports and exercise, promote the normal growth of organs and tissues as well as cultivate a healthier mind. In the past, research in this area mainly focused on the model of aerobic exercise which can enhance the endurance level of cardiopulmonary. While recently more attention has been paid to the important role of strength training on adolescents.

\section{A. Reducing the risks of cardiovascular diseases}

Obesity and Type II Diabetes Mellitus are the two biggest hazards of disease among adolescents. Ogden, $\mathrm{C}$ et al. (2006) highlighted the impact of strength training on the proportion increase of adolescent body fat. They maintained that the amelioration of obesity contributes to decrease the risk of contracting Type II Diabetes Mellitus ${ }^{[5]}$. Although adolescents can ameliorate obesity through aerobic exercise, the excessive weight makes it barely possible for them to complete those typical aerobic exercise (such as jogging). Meanwhile, the excessive load for skeleton and joints increases the risks of injury. Obese adolescents generally show a lack of confidence and a bad mastery of sports techniques when doing sports and exercise. For this reason, they will get bored with the 30-min aerobic exercise with medium load or low load and lose enthusiasm in those demanding sports events (such as ball games). Faigenbaum, A et al. (2008) illustrated the significant value of strength training for obese adolescents. They proposed that the strength training having short intervals between exercise and break is a best fit for adolescents. Li Juan et. al. (2013) applied the interferential resistance training in combination with the six-week aerobic exercise. They conducted an empirical research on 26 adolescents with simple obesity aged from 13 to 14 . As shown in the results, the training method integrating resistance with aerobic exercise can effectively help obese adolescents lose weight and reduce fat proportion and insulin resistance. Apart from the above, this method can also ameliorate the glucolipid metabolism, improve the function of blood vessel endothelium and alleviate the reaction level of oxidative stress and inflammation.

\section{B. Intensifying the bone health}

Strength training was once considered to be harmful for adolescent bone health. But through decades of argumentation, it has been proved that the strength training can promote the growth of bones for adolescents who are living in the crucial period of life. When muscular tissues are elongated or contracted, the force will simultaneously impose the load on the bones for construction and reconfiguration. Loaded exercise is also indispensable for the growth of bones. Adolescents can increase the skeletal growth density at the extreme by ingesting proper amount of nutrition and regularly taking part in the strength training planed for adolescents at specific ages ${ }^{[6]}$. To test the authenticity, the research conducted an experiment on 31 boys aged from 11 to 12 . The boys received a strength training of highly intensive circulation in physical education classes (12min/time, 3 times/week, 20 months). The experimental group and control group were compared with each other to obtain detailed information about the bone growth. As a result, the experimental group with interferential training has witnessed a conspicuous increase in the content and area of bones on the surface of their periosteum and endosteum. Though the peak bone mass is largely affected by heredity, adolescents can improve their bone health by targeted strength resistance training and regular sports and exercise that stimulate the contraction of skeletal muscle. With various effective modes of exercise, adolescents can grow bones in correspondence with the load and intensify the density and strength of skeletons. For example, adolescents can do compound exercise of stretching and flexing, such as compound jumps, and take medium and high intensified strength training involving the synergy movement of multiple joints, such as bench press, squat and weightlifting.

\section{Enhancing the mental health}

Adolescents will positively change their attitudes towards physical education, physical fitness test and the concept of lifelong sports after receiving scientific training (including strength training). Another experiment was conducted to interfere with adolescent sports and exercise. Forty three Canadian juveniles aged from seven to twelve received 12-week strength training with aerobic exercise. It was found that the informants significantly improved their self-efficiency and auto-rhythmicity except for BMI, strength and endurance of cardiopulmonary. In summary, trainers are required to follow the steps below in order to promote the mental health of adolescents: 1. Making scientific and gradual training plans in adaptation to the psychological characteristics of juveniles at different ages; 2. Paying constant attention to what juveniles need for development; 3. Making adolescents recognize their excellent body performance through encouragements and compliments. Conversely, adolescents will suffer great pain emotionally and psychologically if receiving training of high intensity and density, or guidance with excessive pressure, or incorrect methods that emphasizes overloaded exercise. Moreover, ethic issues and use of drugs should also be highlighted to avoid seeking for quick success 
because those instant benefits may indelibly influence the physical and psychological health of adolescents.

\section{Enhancing the performance of sports techniques}

Strength training is an important part of sports training. It can effectively enhance the participants' mastery of sports techniques and performances. During the experiment on young basketball players, 111 boys from the sports school in Hubei Province took part in a three-month training. Thereinto, eight weeks aimed for core strength training and four weeks for explosive power training, both lasting 2-4 times per week and 60 minutes one time. Consequently, the training method combining core strength with explosive power significantly enhanced the strength quality and sports performance of juvenile basketball players. Through a series of studies, it is proved that the strength training can best improve the sports techniques of adolescents if integrating with compound exercise of stretching and flexing. Both modes coordinate with each other and thus create a compound effect far better than any single mode. In order to directly display the effect of strength training, trainers should pay particular attention to the model and the way of directional movement when making training plans. They should also make sure that the improved muscle force is connected with the way in which the force is generated to fit for a specific sports technique. Furthermore, adolescents should simultaneously enhance the strength quality of muscles and the performance of special sports techniques. The muscular strength function of adolescents aged from seven to nineteen depends upon the movement model, speed, contraction type and strength. Therefore, this training incorporates the specific modes of exercise and force to accord with the training target (special sports performance or physical fitness test). Only if adolescents take full use of this training, can they perform the best and acquire the sports techniques.

\section{E. Preventing injuries when doing sports}

With the increase of physical education classes and extra-curriculum sports activities, more adolescents are troubled with sports injury. Some injuries got in the adolescent period may give rise to adult or old-age osteoarthritis in the future. At the same time, injury has also become the major reason for which young players quit their sports career in advance. Ordinary adolescents, parents, PE teachers and responsible leaders at school all show great concern about the hazard of injury. Gradually adolescents find it harder to engage in sports and exercise, which leads to their lack of physical activities. There have been multiple studies on the prevention measures of adolescent sports injury. It is proved that the gradual training plan which is scientifically designed and severely supervised (including strength training) can effectively reduce the occurrence rate of sports injury. By means of six international search engines, a comprehensive statistical research was conducted to analyze the occurrence rate of adolescent sports injury and the corresponding prevention measures. 27561 young athletes aged from 10.7 to 17.8 got involved in the experiment. According to the statistics, the rate of sports injury was about 0.54 . Fewer players got hurt when doing compound exercise such as jumping and fast stretching and flexing. Young girls seemed more sensitive to this inferential strategy. Combined with loaded exercise of stretching and flexing, this Strength training effectively refrained adolescents from getting injured. Numerous empirical studies have confirmed that adolescents can prevent and reduce injuries through regular training. Those training programs introduce correct modes of exercise to learners and impel them to attend strength training, balance training and fast exercise of stretching and flexing. However, due to different skeletal muscular systems, adolescents are able to endure pressure of different loads. Hence, more emphases should be laid on the control of load cumulant in various sports (such as strength training and games). With sufficient break between sessions and during practice in single units, the body can take time to completely get recovered ${ }^{[7]}$.

\section{CONCLUSIONS}

To sum up, strength training is one of the most important exercise for adolescents to strengthen their bones, firmly reset their joints and enhance their muscular strength. If adolescents utilize correct and reasonable sports techniques, they can gradually manage to fight against the resistance source or their own weights in use of the physical movement systems. This method can also intensify the functions of skeletal muscular systems and integrate the ways in which the movement system works. With this foundation, adolescents are ensured to do sports more safely and effectively. However, since most parents, juveniles and even PE teachers are lack of right recognition of strength training, the strength exercise are always being neglected. Thus, the situation allows of no delay that theoretical and empirical studies should be conducted based on the specific circumstances of domestic adolescents as well as the relative research achievements both at home and abroad.

\section{ACKNOWLEDGMENT}

The present study was supported by the National Social Science Foundation of China (13CTY027).

\section{CONFLICT OF INTEREST STATEMENT}

All named authors hereby declare that they have no conflicts of interest to disclose.

\section{REFERENCES}

[1] Roberts SJ1, Boddy LM, Fairclough SJ, Stratton G. The influence of relative age effects on the cardiorespiratory fitness levels of children age 9 to 10 and 11 to 12 years of age. Pediatr Exerc Sci. 2012 Feb;24(1):72-83.

[2] Golding J1, Northstone K, Gregory S, Miller LL, Pembrey M. The anthropometry of children and adolescents may be influenced by the prenatal smoking habits of their grandmothers: A longitudinal cohort study. Am J Hum Biol[J]. 2014 Aug 18:122-126.

[3] Hong Junrui, YUAN Qiongjia, WANG Tao, LI Xue, CHENG Yi, ZHUSNG Jie, CHEN Peijie. The application of Actigraph GT3X sensor to the testing of energy consumption in teenapers' physical exercise. Journal of ShangHai University of Sport.2013,37(3):64-65.

[4] LI Hai-yan, CHEN Pei-jie, ZHUANG Jie. Application of motion sensor 
of surface acoustic wave to measuring teenagers' level of daily physical activity. Journal of ShangHai University of Sport. 2010,34(3):46-48

[5] Wang Chao. Recommendations of physical activity for enhancing health in Chinese children and adolescents. Doctoral Dissertation. Shanghai University of Sport..2013.

[6] LUO Xi-juan, WANG Zheng-zhen, ZHANG Jun, SUN Jun-zhi,
LIQiang. Application of energy consumption code scale of physical activities in exercise prescription. Journal of Beijing Sport University.2013,36(9):76-80.

[7] Adams, J. Trends in physical activity and inactivity amongst US 14-18 year olds by gender, school grade and race, 1993-2003: Evidence from the Youth Risk Behavior Survey. BMC public health. 2006,6:1-7. 